\title{
People, practice, and technology: Restoring Giddens' broader philosophy to the study of information systems
}

\begin{abstract}
This paper argues that practice-based management and IS literature has tended to portray a voluntaristic account of human agency that downplays the contribution to emergent social outcomes of more deeply rooted psychological dimensions of the human condition. Within the IS research community, this tendency is exemplified in work using Giddens' structuration theory, which, whilst acknowledging the importance of human interpretive properties, has foregrounded cognitive aspects to interpretation at the expense of important non-cognitive ingredients such as affect and biographical identity. These non-cognitive ingredients are less amenable for study using the structurational model, but receive comprehensive treatment elsewhere in Giddens' work. Accordingly, it is argued that a useful direction for future theory development would be to seek a more balanced account of humans' co-constitutive relationship with technology in practice. This could be achieved by supplementing the structurational perspective, with its primary focus on emergent social structure, with a more explicit engagement with Giddens' broader concern with emergent biographical structure. An initial integrative framework is offered as a first step in this direction.
\end{abstract}

\section{Introduction: How we feel about our selves matters}

Within management research, theories of practice in which social life is viewed as emergent and enacted are increasingly challenging representationalist depictions of organizations and organizational knowledge (for summaries, see Tsoukas 1996, Thompson 2011). Management and IS researchers have achieved much in applying social theory to open up apparently fixed entities - people, organizational routines, information systems, hierarchies - showing these instead to be emergent, contestible processes, and offering a critique of the dualism of individual-society which characterized immediate post-war social science.

In particular, the growth in organizational 'process' literature (e.g. Pettigrew 1987, Chia 2002, Tsoukas and Chia 2002, Carlsen 2006), and its related emphasis on 'practice', in which human 'agency' and social 'structures' are seen as co-constituted, calls increasingly for researchers to treat both people and organizations as aspects of the same unfolding process: a duality comprising both subjective and objective. However, in viewing humans, organizations 
and technology as co-constitutive aspects of unfolding social reality, there has been a tendency to apply a generalised symmetry across all three of these dimensions that deemphasises something humans uniquely bring to social reality that organizations and technology do not: the way in which human agents feel about themselves, which I argue is a powerful ingredient to the 'sense-giving and sense-reading' (Polanyi 1967) process of the interpretive experience itself.

However, if such feelings may be a significant factor in animating and explaining social practice, they remain undertheorised within management and IS research. Existing organizational literature addressing the subjective component of practice is scant: in a recent review of practice theory, for example, Simpson (2009) identifies "the creative and agentive dimensions of practice as areas that require further theoretical development" (2009:1330). Drawing on Schatzki's (2001) review of the practice literature landscape, Simpson points out that treatments of practice within much of the literature show a primary "concern with the establishment and maintenance of stable and enduring social structures" (2009:1330), rather than the subjective side of the equation. Although she acknowledges that certain studies have succeeded to some extent in illuminating processes of subjective creativity and meaningmaking, for example within science and technology studies/STS (e.g. Callon 1986, Latour 1987, Knorr Cetina 2001), activity theory (e.g. Blackler et al., 2000), and mediating objects (e.g. Orlikowski 2000), Simpson argues that these often do so in a somewhat disembodied way that tends to devalue the subjective experience of agency (2009: 1332).

Simpson's view is echoed by writers within IS (e.g. Sun and Zhang, 2006, Ciborra and Willcocks 2006, McGrath 2006), who have pointed to a wariness in the management and IS literature of portraying an overly voluntaristic view of agency, reflecting "a long history in organizational behaviour of objectifying subjectivity...a relative neglect of emotion in academic ('rational') discourse" (Sturdy 2003: 82-3). It has even been argued that IS researchers, in particular, have adopted a focus on cognitive, over affective, aspects of human agency (McGrath 2006), with a view to discovering how efficient human-computer relationships may best be formed, whose extreme expression might be a discarding of nonrational thought altogether (Brave and Nass 2001).

And yet, if this is the case, it would appear from the literature review in the next section that there may be distinct dangers for IS research in assuming human beings to be more rational agents than in fact they are: not only in the underestimation of social and political factors that may confound rationalist design intentions (eg. Introna 1996, 1997), but also in the difficulties of conducting moral analyses (Avgerou and McGrath 2007), of engaging 
effectively with human experience (Fay and Puyou 2006), of designing consumer-based IT requiring a favourable emotional response (Wan, Chou and Chan, 2009), and understanding the interrelationship between technology and identity (Alvarez 2008), to mention but a few.

In the light of this situation, this paper seeks to make two specific contributions. After a review of the different relevant approaches in IS literature, this paper seeks to move beyond a simple acknowledgement that ideas about the subjective remain under-researched within the management and IS communities. The paper's initial contribution is to draw on neighbouring disciplines, including neurology, psychology and social anthropology, to emphasise the importance of two ideas for management and IS researchers in understanding the subjective: biographical self-identity and affect. It is argued that understanding the specific relationship between these two ideas offers a route to engaging more seriously and productively with the subjective elements of social reality, since it is through this relationship that the enactment of such inscribed subjective structures is carried out. The view is presented that these inscribed subjective structures are every bit as important as the co-emergent social and technical structures that have traditionally commanded more attention within IS research. It is hoped that by providing a clearly defined way to engage with these enacted subjective structures, the paper will contribute to the establishment of these concepts as a mainstream concern within the management and IS literatures.

Although the relationship between biographical self-identity and affect outlined in this paper is derived from recent publications in neurology, psychology and social anthropology, it is argued that increased acceptance and understanding of its workings within these disciplines challenges those of us working within the management and IS research communities to engage in a more urgent and committed way with these ideas. A clear opportunity for the start of such an engagement is the coverage of many aspects of biographical affect and identity in the work of ex-psychologist-turned-sociologist Anthony Giddens, who has written extensively in this area, and with whose work many IS researchers are already familiar. However, I argue that whilst the application of Giddens' ideas has borne considerable fruit within the IS domain, there has been a tendency within IS and organizational studies to date to take and use his 'dynamics of the duality of structure' (Giddens, 1984:29) narrowly, out of the context from which it derives its significance and wider coherence.

It is proposed that the use of Giddens' structurational model in isolation risks downplaying his broader emphasis on the centrality of human motive, so pivotal to his writings, as well as encouraging a focus within IS more generally on cognitive, rather than 
non-cognitive, aspects of social structure, since structuration theory is "one of the most influential...theoretical paradigms influencing IS research in the last decade or more" (Poole and DeSanctis 2004:207). Accordingly, having initially explained why the IS community should engage more with the role of inscribed subjective structures in conditioning social reality, the paper's second, and key, contribution is an exposition of how we may do so using Giddens' ideas. This second contribution occurs via an attempted rehabilitation of IS accounts of structuration theory within the canvas of Giddens' broader writings dealing with non-cognitive components of human agency.

The remainder of the paper is organised as follows. In a first section, two literature reviews establish, first, that there is a normatively cognitivist orientation within the IS literature in general and a relative lack of engagement with concepts relevant to the notion of biographical affect; and second, that this underyingly cognitivist view of human agency continues into IS' structurational tradition. A second section then provides an overview of an increasingly established position amongst some writers within neurology, psychology, and social anthropology, who have identified an important interrelationship between biographical self-identity and affect: I argue that engagement with this interrelationship should become a more urgent concern within management and IS research.

In response, a third section explains the pivotal significance of these ideas within Giddens' work, considered an ideal basis from which to engage with biographical selfidentity and affect. It is argued that Giddens' structuration model per se is not sufficiently representative of Giddens' ideas to be used on a standalone basis as the sole theoretical foundation for a piece of IS research. Responding to this perceived imbalance in the way in which Giddens' ideas are applied within IS, the fourth section then develops a practical framework to complement Giddens' structuration model. This framework is intended to assist IS researchers to include considerations of these wider components of Giddens' thought, resulting in a more balanced analysis which is more representative of his ideas. A short final section considers some of the practical and theoretical implications of this position for the IS community.

\section{1: IS literature and its engagement with the subjective}




\section{1: General}

A short literature review in the IS sector demonstrates a new and urgent interest in many aspects of the subjective, and yet little consensus on how this may be best understood and appraised. There appear to be four discernible areas of concern: papers calling for a more committed engagement with, respectively, existential/non-rational, phenomenological, noncognitive/affective, and identity-related aspects of human-IS interaction. It should be emphasized that these areas overlap and are not intended for any normative, taxonomical purpose. For space reasons, I have not attempted a comprehensive literature review here (although see in particular Sun and Zhang (2006) and Gal and Kjaergaard (2009) for recent reviews, respectively, of affect and self-identity in IS).

A first group of authors calls for greater attention to be paid to non-rational ingredients in processes of IS innovation. This call is exemplified by Avgerou and McGrath (2007), in which the authors argue that in spite of ample evidence to the contrary, mainstream writing "assumes that IS innovation is driven by the rational capabilities of IS and user professionals to derive unambiguously the benefits and risks of the innovation and then steer action toward associated targets" (2007:295), an approach they term technical rationality. In response, Avgerou and McGrath argue that a more realistic appreciation of the human-IS relationship requires paying greater attention to existential concerns and power relations; indeed, McGrath (2006) points out that an appreciation of emotions is required for any conceptualization of IS as a field of moral and political struggle. Other notable calls for greater acknowledgment of non-rational components within human-IS interaction within IS research include Robey and Markus (1984), Walsham (2000), Ciborra (2002), and Avgerou et al. (2004).

A second group of authors calls for further attempts on the part of IS researchers to engage with the "inner life of the actor, mind and heart" (Ciborra and Willcocks 2006:129) of phenomenologically-experienced reality. An empirical example of the way in which phenomenological studies of the 'inner life' can enrich our understanding of IS is Fay and Puyou's (2006) study of users' interaction with management accounting systems (MAS) in a French retailing company, in which they found that MAS were abstract representations that, in spite of imposing a 'common horizon' amongst employees, actually had very little (structural) determination on employees' experience of the situation. The authors cite the phenomenologist Henry's assertion that "structures determine the subject's experience but the living being over determines structures" (2006:2), which may perhaps be considered a significant problem for IS research in general given that "very little research has shown how people actually and subjectively experience Management Accounting Systems" (2006:2). In spite of these valuable exceptions, phenomenologists such as Introna (1996) have highlighted 
the way in which rationalist assumptions can often persist within IS studies, even where there is a stated intention to pay greater attention to their psychosocial context.

A third group of authors calls for greater attention to non-cognitive components to human behavior within the IS literature. For example, Kim, Chan and Chan (2007:511) point out that "the focus of research on IT adoption and post-adoption or IS continuance has been on mainly cognition-oriented behavioral models, such as the technology acceptance model (TAM) (Davis, 1989; Davis et al., 1989), the Theory of Planned Behavior (Ajzen, 2001) and the IS continuance model (Bhattacherjee, 2001)". In response, the authors advocate a 'balanced thinking-feelings model of IS continuance' that explores ways in which cognitive ('thinking') and non-cognitive ('feeling') combine to form a subject's attitude to an IS environment, which in turn creates behavioural intention and resulting behavior. Kim, Chan and Chan (1997) and Wang, Chan and Chang (2009) demonstrate that this more balanced approach is particularly useful for understanding the context of modern, consumer-oriented applications such as mobile internet services and Web 2.0 apps more generally, which must satisfy emotional as well as functional criteria - a point to which I return in the final section.

These findings are supported by Sun and Zhang (2006), who examine deficiencies in various existing theories and models within IS in explaining users' behavior, which they argue may be due to the influence of affect. Based on a recent, comprehensive literature search which resulted in a total of 51 papers with affect and IS foci, the authors cite numerous examples confirming that "affect does matter in determining users' behavioral intention and actual usage behavior. Affect also has significant influence on cognitive factors" (2006:36), and call for more attention within the IS community to affect-related phenomena. Indeed, in an engaging experiment involving behaviours in an e-auction, Adam et al. (2010) provide an account of the way in which emotional factors mean that human agents often continue bidding beyond the point at which they have cognitively set limits, indicating the ability of affective behavior to overrule, or eclipse, cognitively-established constraints.

The fourth discernible, even less researched, area of related IS literature is the important notion of identity. In a useful review of identity-related studies within the IS literature, Gal and Kjaergaard (2009) performed a search of six top-ranked journals in the IS field, yielding 395 articles that mentioned 'identity', only 11 of which used the term in any substantial, theoretically-informed way. Of these 11, only five articles address the interrelationship of technology and individuals' identity in the context of IS implementation: Van Akkeren and Rowlands' (2007) use of social actor theory to analyze the relationships among radiology practitioners, the technology, and the context; Gal et al.'s (2008) study of the effects of the implementation of $3 \mathrm{D}$ technologies within the architecture industry on organizational identities and cross-organizational change; Alvarez' (2008) study of the co-construction of 
identity and IS in which technology, structure, and identity are mutually constitutive; Barrett and Walsham's (1999) study of the implementation of an electronic trading system in the London Insurance Market, drawing on Giddens' ideas to examine its impact on users' selfidentity; and Barrett and Scott's (2004) analysis of the ways in which reflexive self-identity (drawing again on Giddens) is impacted by increased globalization and ICT during the adoption of an e-trading system.

Gal and Kjaergaard (2009) conclude by commenting that "our review of the leading IS journals revealed that the concept of identity work in organizations is seldom used by researchers in the field. When it is employed, it is mostly done without theoretically engaging the concept or leveraging the insights that could be yielded from its application. This finding stands in stark contrast to the overall trend in other management disciplines" (2009:7). More worryingly, only two of the above five studies that deal with the notion of identity in any substantive way, Alvarez (2008) and Barrett and Scott (2004), may arguably be said to engage in a committed way with emergent individual identities, as opposed to more structural relationships amongst organizational participants.

The above short review of IS literature calling for greater engagement with existential/non-rational, phenomenological, non-cognitive/affective, and identity-related components of human-IS interaction support the argument that a substantive domain of human experience is becoming increasingly recognized as important within the IS literature, but that it remains poorly theorized and understood. Approaches to IS that draw on structuration theory might be expected to articulate more fully with theories of the subjective, since the model invites explicit engagement with the relationship between individual agents and social structure. Accordingly, the next section examines the extent to which existing literature within IS' structuration tradition successfully engages with this generally underresearched domain of human experience.

\subsection{Work drawing on structuration}

Jones and Karsten (2008) provide arguably the most comprehensive and thorough review to date of the use of Giddens' structuration theory within IS research, identifying 331 IS articles citing Giddens' ideas. Their paper offers an accordingly ideal basis for an assessment of the degree to which concepts associated with the subjective have featured within IS' structuration canon to date. Jones and Karsten divide the body of articles within this tradition into three groups: first, those articles that 'take structuration theory as a given' and explore how the theory and associated concepts may inform IS phenomena; second, those articles that have attempted to develop IS-specific versions of structuration, of which 
DeSanctis and Poole's 'Adaptive structuration theory', or AST (e.g. 1994) and Orlikowski's 'duality of technology' (1992) are perhaps the most notable examples; and third, a 'critical' strand of research, within which the present paper is situated, exploring the limitations of structuration theory. In assessing the extent to which the existing IS-structurational literature addresses affective or non-cognitive components of human interpretive work even in a more general sense, I will briefly address each of these three groups of articles in turn. Detailed engagement with the structurational model itself and its relationship with the broader hinterland of Giddens' ideas is reserved for the third section of this paper.

Taking, first, those IS papers that 'take structuration theory as a given', I have been unable to locate any studies that seek consciously to situate use of the structurational model within an explicit acknowledgment of, and engagement with, Giddens' writings on noncognitive, biographical components to human experience. Despite Giddens' emphasis on the importance of unconscious/conscious sources of motivation in biographical, hence irreversible, time in explaining social action, and of other, periodical 'bow shots' from commentators such as Knights and Willmott (1989), and Boland (1993), accounts of motivation are almost entirely absent from the majority of IS and organizational studies in this category.

In several early studies involving the application of structuration within an IS-specific context, several scholars, for example Orlikowski and Robey (1991) and Orlikowski (1992) have been successful in conceptualising the duality of social structure. However, they did not balance these insights with the sorts of consideration of motivation which, it will be shown, feature prominently in Giddens' work. For example, Orlikowski's landmark study describes very well how consultants' use of tools is influenced by Beta's institutional context, but the ways in which the tools mediate consultants' perceptions through interpretive schemes, norms, and resources, and the way in which the use of the tools reaffirms these modalities tends to presume motivated agents. Her study makes no attempt to account for ways in which agents' positionality, or stance, towards social-technical interaction may be (strongly) conditioned by their feelings about themselves and the circumstances in which they see themselves as situated. In this way, it becomes difficult to sustain Orlikowski's claim that structuration offers a balanced conceptual mediator between subjective and objective conceptions of organizations (1992:403).

A somewhat rare exception in this category of the literature is the type of study that seeks to apply Giddens' ideas in a 'meta-theoretical' (Jones, 1999) manner, thus arguably avoiding the need to uproot the structurational dynamic from the more 'subjective' aspect of Giddens' writings and transfer it into another context. For example, Hayes and Walsham (1999) examine the very different experiences of computer hardware engineers in their use of 
a laptop-based work co-ordination system for travelling repair agents. Summarising three of these, Walsham notes:

What is immediately striking about these stories is the radically different conceptualisations of the nature of their job, their own identity, including their work identity, and the role and perceived value of IT systems in their work life (2001:73).

Although in his (2001) book, Walsham later acknowledges the role of peoples' identities in conditioning their reactions to, and manner of using, the IS, in this study, engagement with this dimension does not form the authors' primary concern. Similarly, Barrett and Walsham (1999) make an innovative attempt to interpret the impact of the introduction of new electronic trading systems into the London insurance market using a more rounded set of Giddens' ideas. In so doing, they succeed in preserving the anchoring of these ideas to individual motivation and meaning through an explicit treatment of the emergent coevolution of traders' self-identities and wider organizational structure, although they do not adopt the sort of explicit focus on the conditioning effects of narrative structure which is developed below. Rather, their primary focus is the structural relationships amongst participants in insurance brokering.

Other attempts to use Giddens' later ideas within an IS-specific context include Jin and Robey's (2008) study of the technical and social issues engendered by the effects of timespace distanciation in an internet startup company as it grew and developed increasing social and technical interfaces (see also Nicholson and Sahay 2001). A further example explores the notions of risk within IS-enabled conditions of modernity (Scott 2000). However, reflecting "the small number of papers in these categories as a whole" (Jones and Karsten 2008:139), such treatments of the subjective are sparse within the IS literature and, whilst successfully achieving various respective aims, do not seek any committed engagement with the concepts discussed here.

Within Jones and Karsten's second category of papers that have attempted 'IS-specific versions of structuration', this review further limits itself for space reasons to discussing DeSanctis and Poole's Adaptive Structuration Theory ('AST', e.g. 1994) and Orlikowski's 'duality of technology' (1992) and 'practice lens' (2000). AST, in particular, has sought to isolate the structurational model from the broader context of Giddens' other writings, from where it has been transformed into an approximation of 'technology=structure', vs 'organizational actors = agency', leaving the dynamic stripped almost entirely of supporting theoretical context (see also Maznevski and Chudoba, 2000). Jones and Karsten (2008) usefully quote DeSanctis and Poole's encapsulation of AST's primary proposition, as follows: 
"Given advanced information technology and other sources of social structure...and ideal appropriation processes, and decision processes that fit the task at hand, then desired outcomes of advanced information technology will result" (DeSanctis and Poole 1994:131, in Jones and Karsten 2008:141). Here, AST's primary concern with predictive design along cognitive lines is clearly discernible, with little or no engagement with non-cognitive, in all likelihood less predictable, affective dimensions in structuring social outcomes.

Orlikowski's 'duality of technology' (1992) has been similarly influential, in which technology is seen as 'hard' structure that both enables and is constrained by human action, and is thus 'intepretively flexible'. A particular strength of this approach has been a questioning of technologically determinist positions that view technology as a given, and an encouragement for researchers to engage with contextual factors that may contribute to such enabling and constraining effects. Although she acknowledges that such factors may include power, knowledge and interests involved in human action - together with unintended consequences of such action - human agency is again viewed from a primarily cognitive perspective. In contrast to her 'duality' model, Orlikowski's 'practice lens' (2000) approach sees a softening of her earlier 'hard' technological structure to the emergent structure of 'technology in practice' - nonmaterial routines that would seem to offer a potentially more promising way of engaging with enabling/constraining subjective dimensions of social generation:

Thus, rather than starting with the technology and examining how actors appropriate its embodied structures, this view starts with human action and examines how it enacts emergent structures through recurrent interaction with the technology at hand (Orlikowski 2000:407).

Although this modified approach to emergent structure undoubtedly offers the basis of a powerful framework for engaging with a broader range of emergent structures, there remains the important question of 'which ones?'. Within the practice lens, the primary focus is on "these enacted structures of technology use, which I term technologies-in-practice" (Orlikowski 2000:407). Neither Orlikowski nor any of those who have made use to date of the practice lens have focused on those non-cognitively experienced, subjectively emergent structures discussed here that also condition agential interpretation, and thus enactment, of technologies-in-practice. Following Orlikowski's terminology, such structures might be termed 'selves-in-practice', and would be amenable to study via her model.

Third and finally, within Jones and Karsten's 'critical' strand of IS-structurational papers, there is again no significant attempt to date to suggest ways of using structuration 
alongside other theoretical approaches or interdisciplinary evidence to engage in a committed way with the non-cognitive and set out its component parts. Such a lack occurs in spite of several individually valuable attempts to engage with aspects of structuration that undoubtedly have bearing on these ideas, most notably issues of power (e.g. Brooks and Atkinson 2004, on actor network theory, and Dobson, 2001, on critical realism). In the next section, I set out some insights from other disciplines which demonstrate that it is possible, even urgent, to gain a more developed theoretical grasp of these subjective and emotional dimensions.

\section{2: The important linkage between biographical identity and affect}

Having established that ideas relating to non-cognitive human behaviour are undertheorised within the IS and IS-structuration literatures to date, I now present a summarised argument for the particular importance of two of these ideas, biographical identity and affect, for those seeking to understand the interrelationship between humans and technology. This argument centres on the notion that people draw upon feelings of selfpositioning and identity in their biographical past as well as anticipated future to produce a particular, animated stance towards their social interactions in the present: a specific formulation of affect that, as I will later demonstrate, has particular resonance with Giddens' writings. In making my argument, my intention is to persuade the reader that the absence of committed interaction with these ideas within the IS literature may constitute an important omission, as well as missing a potentially rich source for future theory development, to which I turn in Sections 3 and 4.

It may be appropriate to begin with an acknowledgement that the management studies and IS communities already pay a high degree of attention to explanations of social practice that are based on the way in which human intentions and intersubjective expectations form and operate. Structures that facilitate intersubjectively convergent, and thus mutually intelligible, expectations have been developed within the management and IS literatures drawing on concepts from other disciplines including Bourdieu's habitus (1977), Goffman's frames (1974), Holland's figured worlds (1998), Schank and Abelson's scripts (1977), Kant's schema (1933), and Leontiev's activity (see Wertsch 1981) - even Lave's situated learning:

Settings, persons-acting, and activity intersect in the construction and playing out of what might be called expectations rather than goals. ...Expectations, dialectically constituted in gap-closing processes, enable activity while they change in the course of 
activity, backward and forward in time and at the same time. People act inventively in terms of expectations about what has happened, is happening and may happen. And these in turn affect what does happen" (Lave 1988:184-5, original italics).

If intersubjectively-shaped, subjectively-experienced expectations and intentions form important rules and resources, or structures, for social generation, then it would appear important to understand more about this important process. We know quite a lot about the extent to which these derive from cognitively derived calculation, as this is the territory of the great majority of the management and IS literature, as shown earlier. What we know less about is the extent to which such structures-in-practice may be also coloured by non-cognitive factors, less visible to the researcher.

The work of the neuroscientist Damasio is widely-cited and acknowledged as significant amongst those advocating greater attention to the non-cognitive aspects of human experience. Damasio (1994) discovered that people experiencing affective impairment and consequently unable to 'feel' in normal ways also experienced cognitive impairment concluding that rationality and emotion are so intertwined as to be incompletely distinguishable, and that "nature appears to have built the apparatus of rationality not just on top of the apparatus of biological regulation, but also from it and with it" (Damasio 1994:128). He further concludes (1999) that the rational is built out of the affective, that consciousness is a form of feeling, and that it

...provides the organism with an elaborate sense of self - an identity and a person, you or me, no less - and places that person at a point in individual historical time, richly aware of the lived past and the anticipated future, and keenly cognizant of the world beside it (Damasio 1999:16, my italics).

Clearly discernible in the above passage is the establishment of the importance of a biographical awareness (the 'elaborate sense of self' in 'individual historical time'), which allows a person to position herself relationally against unfolding social reality ('the world beside it') - as well as the clinically-based assertion that this juxtaposition occurs within consciousness - which is felt affectively. Others writing out of the clinical tradition have built further upon the important insight that cognitive structures may be experienced, or felt, non-cognitively, and that this process is deeply linked to our apprehension of time. For example, in the significantly titled book Feeling, being, and the sense of self (2007), West has argued that "identity, affect and object relations have, therefore, been shown to be intimately linked and interrelated" (West 2007: 235). West draws on Damasio's insights, even going so 
far as to propose an 'identity-affect model' that enshrines this crucial link between historical identity and felt consciousness, highlighting in particular the evaluative implications of this process. Consciousness

...not only "represents" yourself, it also tells you how you are doing...[it] is not only intrinsically introspective...it is also intrinsically evaluative. It imparts value. It tells us whether something is "good" or "bad"; and it does that by making things feel good or bad (or somewhere in between). That is what core consciousness, or feeling, is for. (Solms and Turnbull 2002: 90-1, in West 2007: 36, original italics).

For a growing number of writers within the psychological tradition, temporally-based, affectively-felt consciousness is deeply relational, and thus structuring of, our stance towards unfolding social reality. The psychologist Barbalet (2001) has provided a useful account of the way in which this conditioning stance is formed: also, like West, proposing that this occurs through an interplay between a historical sense of self, emotion, and social structure. Barbalet suggests that our sense of historical person-hood - experienced as an inchoate feeling - helps us to pick out what we find relevant about our surroundings and, in so doing, our feelings about our situation condition our state of expectancy, since we are always preparing for action. Recalling Damasio's earlier-stated position, a particular feature of Barbalet's work is the pivotal importance of a temporal dimension, in which the anticipated future becomes important as well as the recalled past:

Expectancy, as an apprehension of a possible future, is also an interpretation of the past: the direction of action is conditioned by its point of departure and the resources bequeathed to it by previous actions. Expectancy, in terms of what it leads an actor to do at any given time, also situates that actor in the present. It is in this sense, then that emotions are at the root of apprehensions of temporal order. Indeed, this is emotion's unique contribution to action and agency: without it, persons would be lost in time, the past would remain remote, and the future inaccessible (ibid.:185, italics added).

Drawing these insights together, I have presented the view that although various component concepts within the subjective domain such as identity, emotion, and noncognitive processes are already receiving greater attention within management studies (e.g. Fineman 2008), we should start to engage in particular with the possible ability of the particular relationship between biographical identity and affect to structure our stance towards, and thus condition, emergent social reality. As a final possible motivation for researchers in this regard, Barbalet's work highlights the 'reconciliatory potential (Sturdy 
2003) of emotion in challenging dualistic analyses, and in linking subjective and objective, past and present, structure and agency, and macro-micro debates:

All action changes the context of future action and of past events. It is the actor's emotional apprehension of time which constitutes the basis of action, and gives it direction and form. Emotion, as movement, is in that sense both external to the subject who experiences it and integral to their being as a consequence of their being moved by the feeling. Emotion has a source outside of the self in its relations with others and is internally experienced as a function of active being. It is through the subject's active exchanges with others, through interaction, that emotional experience is both stimulated in the actor and orientating of their conduct. Emotion is directly implicated in the actor's transformation of the environment, and the environment's transformation of the actor" (Barbalet 2001:187).

In Sturdy's view, (2003:83), emotions can be seen as multidimensional 'complexes' or 'modes of communication' which are both cultural and corporeal/embodied (see also Williams and Bendelow 2008), and arise in practice. Such a multidimensional conception of biographical self-identity and affect can be summarised as 'biographical affect', and arguably improves our ability both to engage with and to explain the temporality of practice, in its ability to colour the 'chordial triad of agency' itself, defined as

The temporally constructed engagement by actors of different structural environments the temporal-relational contexts of action - which, through the interplay of habit, imagination, and judgment, both reproduces and transforms those structures in interactive response to the problems posed by changing historical situations (Emirbayer and Mische 1998:970).

Engaging with non-cognitive components of interpretive activity allows us to encounter the conscious and unconscious affective motivations contributing to peoples' habitually, imaginatively, and judgmentally-derived stance towards social structures with which they may be confronted in the present. In offering an impelling dynamic overcoming traditional dualisms, biographical affect both animates and explains the underpinning motives for important dimensions of rationally-oriented social practice. In showing rational agency to be both affectively-motivated as well as cognitively organised, such an interpretation allows theories of practice to ask not just how but also why. 
Having sought to establish the need for a more committed engagement within management studies and IS with non-cognitive, subjective dimensions of human experience in general and with the structuring potential of biographical affect in particular, the remainder of the paper explores the rich potential of Giddens' writings as a source of theory development in this regard. The following sections seek to establish that such concerns are already well-established within Giddens' writings, of which his structurational model alone should thus not be taken as representative, before offering a complementary framework for using these ideas alongside the structurational model itself.

\section{3: The pivotal role of motive in Giddens' work}

\subsection{Actors have 'good reasons' for what they do}

Although Giddens has produced a consistent output since 1971, the majority of his ideas referred to here relate to earlier stages of his career, during which he focused on a reinterpretation of many of the dualities underlying traditional sociology, of which notions of 'structure' and 'agency' were prominent. Such concerns appear much less in Giddens' later works, which show a primary concern with re-evaluating traditional political polarities in the light of conditions of modernity, most notably in the articulation of a 'Third Way' (1998), although these works are cited where relevant.

It is arguable that a keen attention to the importance of peoples' motives for behaving in the way that they do runs throughout the broad canvas of Giddens' thought, and indeed, endows it with much of its integrated character. Underlying his ideas is his treatment of the deeply-embedded dualism within the social sciences between objectivism and subjectivism, and the extent to which the social object of study should be 'society', as opposed to the individual. An awareness of this dualism - and the 'duality' which he proposes for its resolution - runs throughout Giddens' work, providing the basis for several of his key ideas. Perhaps the most fundamental expression of this duality occurs in The Constitution of Society (1984), where Giddens proposes, in the 'double hermeneutic', the impossibility within social science of keeping the conceptual apparatus of the observer free from involvement in the situation being studied. In interacting with the social world, a person's thoughts are deeply linked to wider social structures - an observation responsible for the theory (like activity 'theory', and actor network 'theory', also really an ontology) of structuration, which describes the process whereby the 'absent totality' of social context is continually drawn upon and reconstituted in social interaction.

The important point to be made immediately upon presentation of this basic 'duality' is that the majority of Giddens' thought is built upon a particular understanding about the 
centrality of individual motive in social production and reproduction, and hence of the realm of individual interpretation and action, wherein this duality is played out. Giddens achieves this understanding by developing Bourdieu's 'habitus' to place more emphasis on the primacy of the individual as knowledge agent, which allows him to redress the structuralist/poststructuralist decentring of the subject within structuralist linguistics. Indeed, in The New Rules of Sociological Method, he places peoples' interpretive activity at the centre of his analysis, citing it as a key differentiator of his ideas in relation to structuralism, which "bears the limitations of its origins in its inability to confront issues of the genesis and temporality of meaning" $(1976: 126)$.

In contrast, meaning is central for Giddens, who is influenced by Goffman's thought on the interaction between the conscious and unconscious in the individual, and the role this plays in the way in which they make sense of the world. Indeed, Goffman's 'frame analysis' has helped to structure Giddens' understanding of the micro-level interactions between individuals, and between individuals and wider society - and, significantly, to address the relationship between the two. However, in his consideration of the agency/structure divide, Giddens differs from Goffman in blurring the line between front and back regions (1984), and distinguishing between three types of consciousness: 'discursive consciousness', 'practical consciousness', and the 'unconscious'. Of these, practical consciousness (as a rational, if 'unaware', response) is the most significant, since it mediates between the agency/structure divide and the conscious/unconscious divide.

Giddens' dynamic of structuration integrates the above concepts into an approach to the study of social interaction. In their everyday encounters of 'co-presence', Giddens argues that individuals both follow and re-create social rules. Since the 'absent totality' of social rules necessarily frames, conditions, and mediates social interaction, the process whereby (like any ideology) motivated people succeed in reflecting their interests within such rules within an organization is shaped by differences in power and resources at their disposal - both in terms of material resources and (after Bourdieu) cultural 'capital' (which might be termed as a collection of acquired social skills which reinforce the individual's ability to meet expectations within social contexts). Once organizational inequalities have been formed (although these are clearly not static in nature), Giddens argues that institutions employ 'surveillance' techniques in attempts to extend and maintain the existing status quo (1984). Giddens conceives of surveillance as taking many forms, from the extension of control over time-space through clock-time, to the future (for example, legislation, commodity speculation), to simple organizational hierarchies.

In offering a conceptual tool with which to look for "connections between legitimation and domination in the constitution of societies" (1981:65), Giddens encourages the researcher 
to seek such connections in the interaction between consciously and unconsciously motivated, 'purposive, reasoning behaviour', and social constraint/enablement. It is thus fitting that the following passage is to be found in, of all his works, The Constitution of Society:

The actors have 'good reasons' for what they do, reasons which the structural sociologist is likely to assume implicitly rather than explicitly attributing to those actors...all explanations will involve at least implicit reference both to the purposive, reasoning behaviour of agents and to its intersection within constraining and enabling features of the social and material contexts of that behaviour (1984:178-9).

The position of individual motive as the driving logic behind social production and reproduction is especially visible in The Consequences of Modernity, which centres on the individual's experience of modernity, rather than 'modernity' itself. Thus characteristics of modernity such as time-space separation, disembedding mechanisms, and reflexive appropriation of knowledge, are all emergent properties linked to the individual's perceived risk, and capacity for trust, in relation to his or her attempts to moderate an irreducibly personal experience of modernity and maintain ontological security.

In turn, Giddens proposes that such attempts are only explainable in relation to their "reflexive constitution of self-identity" (1991:86) within the narrative of a perceived trajectory of the self. Drawing on Heidegger and the time-geographer Hagerstrand, he proposes that there is an inherently temporal character to human existence - the "temporality of meaning" alluded to earlier. Such a position entails a distinction between three types of temporality, "of very considerable importance"(Giddens, 1984:36):

"Daily life has a duration, a flow, but it does not lead anywhere; the very adjective 'day-to-day' and its synonyms indicate that time here is constituted only in repetition. The life of the individual, by contrast, is not only finite but irreversible, 'being towards death'. 'This is death, to die and know it'"(1984:35).

These two types of experienced temporality - reversible and irreversible - intersect with each other, and with 'the 'supra-individual' durée of the long-term existence of institutions, the longue durée of institutional time" (1984:35) - like daily life, another reversible dimension. Crucially for the thrust of this discussion:

"Theorizing the self means formulating a conception of motivation (or so I shall argue) and relating motivation to the connections between unconscious and conscious qualities 
of the agent. The self cannot be understood outside 'history' - 'history' meaning in this case the temporality of human practices, expressed in the mutual interpolation of the three dimensions I have described" (1984:36).

Although Giddens' works can appear at times to resemble the Bible, in the way in which it is usually possible to find a passage supporting (out of context) whatever standpoint one wishes to adopt, it is arguable that the above statement is consistent with a view throughout his work that the constitution of society through the intentions and practices of people is closely related to dimensions of time-space - the "temporality of meaning" - in particular, the non-reversible dimension. The irreversible temporality of the human agent's bodily involvement - their lifespan - and thus the desire for a coherent narrative trajectory which stems from this - comes to infuse the more empirically 'visible' and reversible dimensions of daily interaction, and of organizational existence. Although invisible, the individual's irreversible condition of "being towards death" - and, crucially, "knowing it" thus affects both of the visible, reversible, dimensions, affecting their motivations within dayto-day social interaction, which come over time to condition wider structures at the institutional level. It is thus no exaggeration to say that an awareness of the irreversible dimension in time-space interaction must be a prerequisite to making sense of Giddens' ideas, since this underlies his conception of motivation - of human experience itself - and thus underpins his view of social production and reproduction in the manner explained earlier. In linking the notions of time, biographical identity and (physically felt, semi-/unconscious) noncognitive awareness, Giddens anticipated work that has subsequently confirmed the importance of these ideas, encapsulated in Section 2 in the term 'biographical affect'.

The link between temporality and motive for Giddens appears most clearly in Modernity and Self-identity, a discussion of the way in which the need reflexively to maintain a consistent biography which stems from a physical awareness of a finite lifespan, comes to condition peoples' perception of, and actions in, the world. Thus Giddens' ideas come full circle, since social production and reproduction are seen to consist in the intended and unintended consequences of the conscious/unconscious interpretive activity of myriad agents, as they pursue the logics - the motivations - of their own reflexively-maintained biographies, within the enabling and constraining conditions of high modernity. Thus, for IS researchers, "technology does nothing except as implicated in the actions of human beings" (1998:82).

In this way, although its focus is the conditioning action of 'social' structure, the underlying logic of Giddens' theory of structuration may be said to derive from his more fundamental view of the cognitively and non-cognitively motivated self-as-process. This temporally-driven, affective side of this motivation, here termed 'biographical affect', has 
lately attracted increased interest within neuroscience, psychology, and social anthropology, but remains underrepresented generally within the IS literature, as well as within IS literature making use of structuration. Such an account of the non-cognitive aspect of human motivation underpins much of Giddens' work, but is not readily available from within the structurational Dimensions. Accordingly, I suggest that 'stranded' in repeatable time, purely structurational accounts of human interactions lose the hidden urgency, and explanatory narrative, through which they derive their meaning and organizational portrayals become literally lifeless: there is no sense of events being driven by and occurring within, peoples' irreversible lives. Interestingly, this is exactly the criticism Giddens directs at Goffman:

...Goffman's analyses of encounters presume motivated agents rather than investigating sources of human motivation, as many of his critics have complained. The lack is a serious one and one of the main reasons... why Goffman's work has something of an 'empty' feel to it" (1984:70).

\subsection{Analysis of 'social' structure is necessary, but insufficient}

Having emphasised the need to use structuration alongside, rather than separately from, Giddens' wider ideas on human motive, this section discusses his 'dimensions of the duality of structure' model (Fig.1.) in greater detail. As a schematic to show what its title indicates it was intended by its author to show - dimensions of the duality of structure, no more, and no less - Giddens' model represents a useful concept with which to approach both an aspect of his thought, and an aspect of the organizational domain. Although it tells us a lot about the nature of social structure, and the way in which this is replicated or subverted through human action, Fig.1. tells us comparatively little about human motivation, or about any of the other rich insights about subjectivity which run throughout Giddens' thought, from which the model ultimately derives its impelling logic, as argued earlier. It is unsurprising, therefore, that Giddens entitles his model 'the dimensions of the duality of structure' - and not, for example, 'dimensions of the emergent condition of subjectivity', 'domains of the emergence of biographical narrative', or 'registers of conscious and unconscious motive in addressing existential anxiety' - since the model is not intended to address these, equally vital, aspects of his thought. We can say this with some certainty, since the model brackets out individual reflexivity to concentrate on social structure:

"Concentration upon the analysis of the structural properties of social systems, it should be stressed, is a valid procedure only if it is recognized as placing an epoché upon - holding in suspension - reflexively monitored social conduct" (1984:30). 


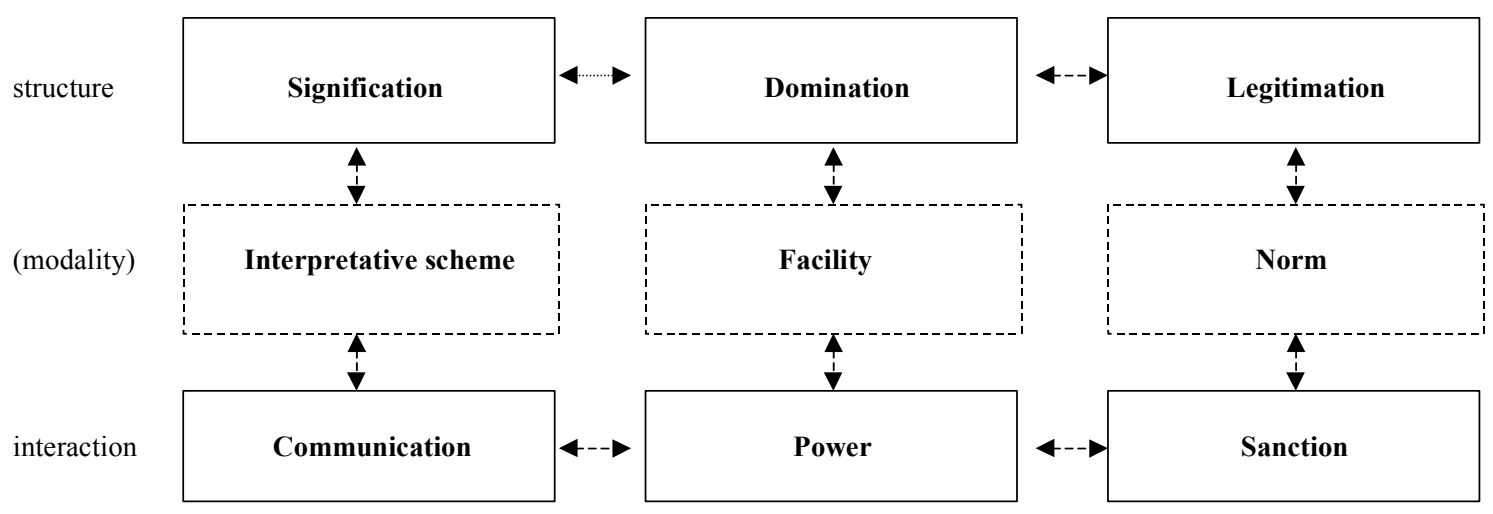

Fig.1.: Giddens' dimensions of the duality of structure (1994:29)

Structurational analysis is therefore useful as a framework with which to study the production and reproduction of social structure - but represents an insufficient basis for IS researchers seeking to study human-IS interaction in any complete sense - since the (for Giddens) equally important, co-ordinating effect of human reflexivity is bracketed out. Put another way, although the figure of the Dimensions portrays a duality, it portrays the social structural side of this duality, rather than the biographical, reflexive side, of which researchers should continue to be aware:

"Reflexive awareness...is characteristic of all human action, and is the specific condition of (that) massively developed institutional reflexivity" (1991:35).

\section{4: Towards a complementary framework}

For those researchers seeking to find ways of incorporating considerations of biographical affect within structurational analyses, Fig.2. shows Giddens' figure of the Dimensions, with an additional, 'biographical' realm of interaction added below, indicating that social interaction draws upon a biographically, as well as merely socially conditioned, realm of structure. It should be emphasised immediately at this point that in introducing this modification to Giddens' diagram, the intention is merely to draw IS researchers' attention to aspects of his wider work regarding human subjectivity which the structurational model, in placing an epoché upon biographical reflexivity, was not intended to illustrate. The additional terms in Fig.2. are thus intended to be used alongside Giddens' figure only in a temporary sense, to illustrate the importance of his wider considerations of such biographical reflexivity in complementing the structurational model as an explanation of social life. Although, as 
shown earlier, such considerations are germane to all his work, the additional terms used in Fig.2. have been derived by the present author from Modernity and Self-Identity (1991), in which Giddens addresses the issue of biographical reflexivity in most detail.

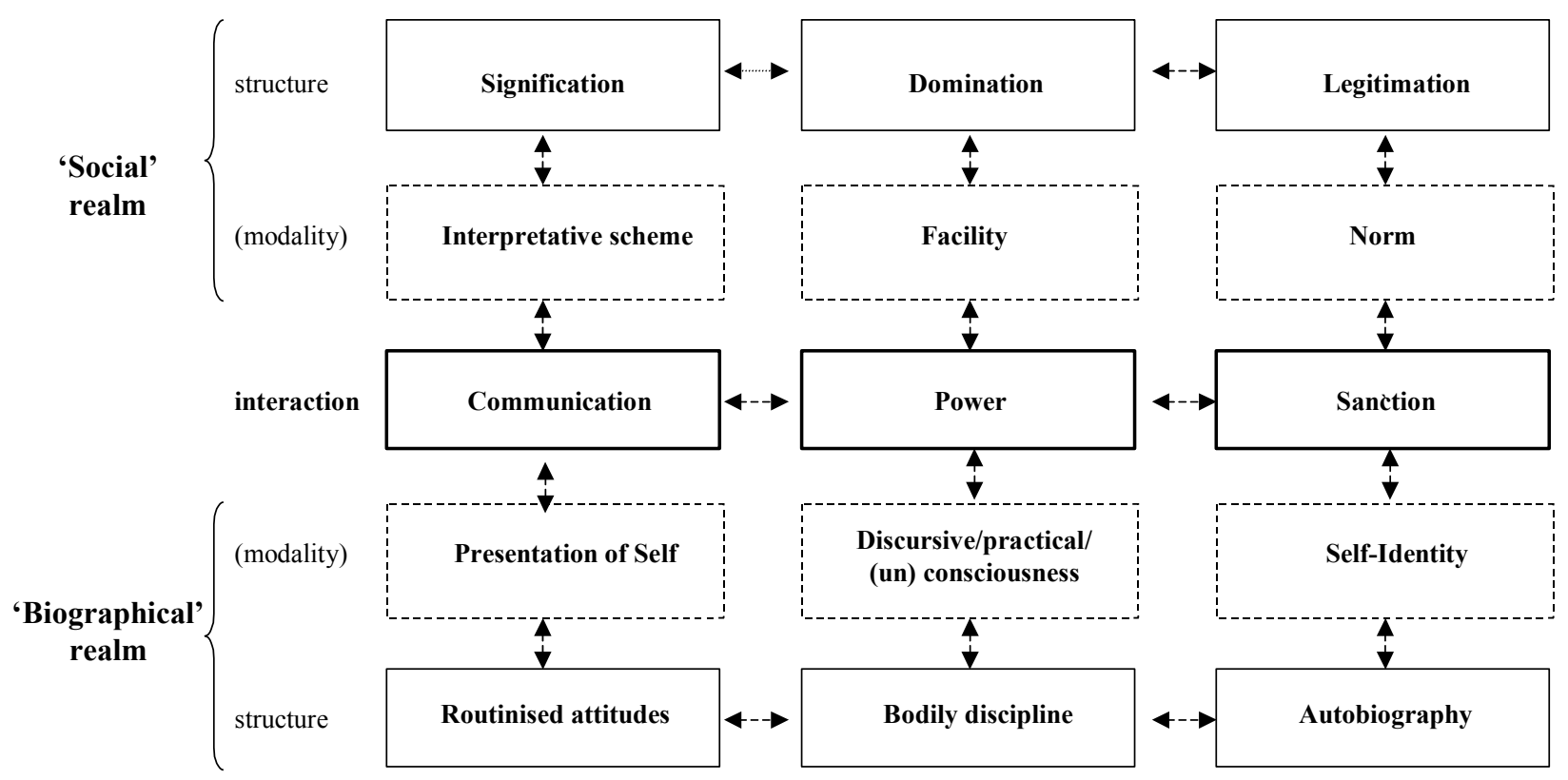

Fig.2.: Dimensions of the duality of social and biographical structure

In Giddens' words, "analysing the structuration of social systems means studying the modes in which such systems, grounded in the knowledgeable activities of situated actors who draw upon rules and resources in the diversity of action contexts, are produced and reproduced in interaction" (1984:25). Thus, structuration analysis involves examining how, in the process of communication, people draw pragmatically upon interpretive schemes to produce and reproduce structures of signification; how they express particular, situated relations of power in interaction by drawing on allocative facilities which both produce and reproduce structures of domination; and how they morally sanction, or justify, these relations by drawing upon social norms which both produce and reproduce structures of legitimation and how these three dimensions are fused in the instant of activity, since "structures of signification are separable only analytically either from domination and from legitimation" (1984:33). As stated earlier, such structures are all social in nature: "rules and resources, or sets of transformation relations, organized as properties of social systems" (1984:25). Below, I explain how IS researchers using the structurational model may wish to consider the reflexive production and reproduction of biographical structures in social interaction. 
Just as (social) "structure has no existence independent of the knowledge that agents have about what they do in their day-to-day activity" (1994:26), so "the self is seen as a reflexive project...dependent on the reconstructive endeavours in which he or she engages" (1991:75) i.e. both concepts are structurally latent, and emergent in human (inter)action. Just as in Giddens' attempt, in structuration, to deconstruct social structure into three dimensions (his three columns in Fig.1.), he advises that when discussing the self "rather than talking in general terms of 'individual', 'self' or even 'self-identity'... we should try to break things down into finer detail" (1991:75). Just, also, as it is necessary to bracket out biographical considerations from structuration in order to study the operation of social structure, so in Modernity and Self-Identity Giddens temporarily brackets out social structure when discussing the trajectory of the self. Thus it is argued that IS researchers seeking to make use of structuration risk applying an incomplete - and therefore misleading - theoretical framework unless they ensure that this is balanced by a consideration of Giddens' equal concerns regarding biographical motivation.

Turning to Fig.2. in detail, within the dimension of legitimation, people draw upon normative values to justify, or legitimate, their actions, and in so doing create and recreate social structures of legitimation. However, as in the case of the other two dimensions of Giddens' structurational model, although this tells us about the way in which social structure is produced and reproduced, it tells us little about the conditioning effects of (cognitively and non-cognitively-driven) individual reflexivity which temper this process - which are bracketed out. For underlying peoples' actions in drawing on social norms to appeal to 'moral' structures of legitimation is a desire to fulfil another, irreducibly personal, morality: "The morality of authenticity (which) skirts any universal moral criteria" (1991:79), and is "based on 'being true to oneself" (1991:78). As indicated in the first part of the paper, it is arguably this desire to enact a coherent personal narrative within the "reflexively actualised trajectory of self-actualisation" (1991:79) - i.e. as understood by a person at any one particular moment - which forms the driving motor, or logic, co-ordinating their actions in relation to the social structures with which they are confronted.

In this way, "The autobiography is a corrective intervention into the past" (1991:72), since it is reflexively produced and reproduced in response to the way in which people feel about their situation; indeed, and recalling the recent, more urgent interest in biographical affect outlined earlier, "Reconstruction of the past goes along with anticipation of the likely life trajectory of the future" (1991:72). Thus "It is made clear that self-identity, as a coherent phenomenon, presumes a narrative" (1991:76). In their continuous generation of selfidentity, or 'self-actualisation', - a particular, unifying conception of themselves at any one 
moment - people thus interrogate, respond affectively towards, and revise cognitively a deeper, narrative 'biographical' structure which extends reflexively into both past and future.

At any moment, therefore, a person has a sense both of social norms, and of their own particular temporary positioning within such norms (self identity) - and one cannot be experienced independently of the other. Just as social structures of legitimation form a referential framework within which social norms at any one moment can 'exist', so, biographical structures of autobiography also form a referential framework within which an equally temporary self-identity can 'exist'. It therefore makes as little sense to consider emergent social norms without the vantage point of emergent self-identity from which they must be viewed, as to consider emergent self-identity in isolation from the emergent social norms in which it must be located. This is especially the case given the increasingly locally renegotiated nature of such norms within modernity, where "[w]e must now deal with an irredeemably pluralistic universe of values, and indeed the suspension of all value judgments, save for contextual or local ones" (1994:20).

Within the dimension of domination in Fig.2, people draw upon allocative facilities available to them, and in so doing create or reproduce wider power structures at the social level. However, the way in which this occurs is likely to be conditioned, not just through the action of structural constraints on their discursive/non-discursive awareness, but at the phenomenological level of practical consciousness, which "is integral to the reflexive monitoring of action" (1991:36). Expressed as tacit, embodied skill (e.g. Polanyi, 1958; Nonaka, 1991), practical consciousness has, of course, formed a core element of the recent interest in knowledge management (e.g. Blackler, 1995; McDermott, 1999). However, Giddens adopts a more political emphasis, citing Merleau-Ponty and Goffman's contention that

"Bodily discipline is intrinsic to the competent social agent... and it is a continuous feature of the flow of conduct in the durée of daily life. Most importantly, routine control of the body is integral to the very nature both of agency and of being accepted (trusted) by others as competent" (1991:57).

From this it follows that social agency is conditioned not just by the way in which people exploit ready-at-hand allocative facilities, rooted in social structures of domination, but also by biographical affect: the nature of reflexive, embodied awareness which each individual brings to, and with which they interpret, their every social encounter. Although not cited by Giddens, it is arguable that Bourdieu's description of 'hexis', below, most accurately describes such embodied awareness: 
"Bodily hexis is political mythology realised, em-bodied, turned into a permanent disposition, a durable manner of standing, speaking and thereby of feeling and thinking. The principles em-bodied in this way are placed beyond the grasp of consciousness" (Bourdieu, 1977:93-4).

In this view, the extent to which individuals' actions are conditioned by (social) structures of domination through the modes of facilities is thus always tempered, or conditioned, by the extent of the individual's discursive, practical, or even unconscious level of absorption or resistance to such facilities - which is rooted, in turn, in the disposition of the embodied self. Just as social structures of domination can emerge replicated or altered as a result of a social encounter, so, too, can the individual's embodied receptiveness to the operation of power within future encounters - recalling Bourdieu's "durable manner of standing, speaking and thereby of feeling and thinking". Within the dimension of domination, it therefore makes little sense to consider the (structurational) operation of power via facilities, rooted in social structures of domination, in the absence of the conditioning effect on such power of individuals' levels of consciousness, and even acceptance, of such facilities, in which bodily discipline at both conscious and unconscious levels is both conditioning and resulting structure.

Within the dimension of signification, actors draw upon interpretive schemes which are readily available to them within a particular interaction, and in doing so reproduce or perhaps alter underlying structures of signification at the social level. Although, however, the interpretive schemes available to individuals engaged in the act of communication may be constrained by social structures of signification, Giddens argues that such individuals remain able to exercise a degree of choice over which schemes to use:

"All individuals actively, although by no means always in a conscious way, selectively incorporate many elements of mediated experience into their day-to-day conduct" (1991:188).

The various acts of communication which may characterise any social encounter therefore represent individuals' own situated responses to the choices and dilemmas posed by "living in the world" (1991:188) of mediated information, where "social reflexivity refers to a world increasingly constituted by information rather than pre-given modes of conduct" (1998:115): of available interpretive schemes - in which those with the skills and education to make use of information technologies stand a greater chance of success (2000:95). By 
choosing some over others, individuals are affirming a position in relation to such schemes (and the social structures by which they are enabled and constrained), and thus defining themselves in relation to these. Thus communication is literally an act of self-presentation i.e. the offering up of a stance towards society and its structures:

"As the individual leaves one encounter and enters another, he sensitively adjusts the 'presentation of self' in relation to whatever is demanded of a particular situation" (1991:190).

In otherwords, the communicative stance adopted by an individual in a social encounter is constrained not only by ready-to-hand interpretive schemes, but also by the presentation of self, or assumed identity, that the individual offers 'the other' as a response to the particular social (structural) configuration within that encounter. Finally, an individual will form a socially appropriate 'self' from the more structural, personal vocabulary of routinised attitudes (1991:188) associated with the avoidance of ontological anxiety. In this way, it has been argued that people enact routinised scripts (Schank and Abelson, 1977) in relation to their individual perceptions of their unique perceived 'position' within social structures. Like all structure, such routinised attitudes can constrain, as well as be altered in turn by, social interaction.

To summarise the discussion of Fig.2, it is proposed that Giddens' ideas concerning social structure, contained within his structurational model, are complemented by a further set of his ideas concerning personal, biographical structure, and the two forms of structure act to constrain the operation of one another at every turn. On the one hand, there is, indeed, a duality between fleeting social interaction and relatively enduring shared social structures, which generates appropriate mental 'modalities' that are approximately shared by social interactants, and which thus come to condition their interaction. On the other hand, Fig. 2 shows a mirrored duality - between the same fleeting social interaction, and relatively enduring non-shared, personal cognitive and non-cognitive structures, which generates its own appropriate (affective) modalities, which also come to condition the way in which people interact.

For social researchers, the implication is that a compelling account of social interaction is likely to comprise an analysis not just of the structuration of social systems, but also of the structuration of personal, or biographical, systems - equally acknowledged by Giddens in his work, but never developed into a Dimensions model. Fig. 2 represents an attempt to begin to conceptualise how such a 'balanced' model might operate. 


\section{Key implications for IS research}

In focusing attention on non-shared, subjective structures, and especially the way in which these are enabled and constrained by temporally-driven, affectively-felt biographical identity ('biographical affect'), I have sought to make four, linked, points: first, that such structures remain under-theorised within the IS canon; second, that Giddens' writings offer a rich source of theory on the unfolding interrelationship between these subjective structures and social structures; third, that Giddens' interest in this area has been vindicated by subsequent research I have outlined earlier linking time, biographical narrative, and affect, confirming this to be a pressing subject with which IS research should engage; and, fourth, that structuration research, in particular, might benefit from a 'corrective rebalance' that draws both from such more recent research, as well as from Giddens' ideas about how such structures may co-evolve with social structures.

It should be emphasised that the organization of Giddens' wider ideas concerning motive into the dimensions in Fig.2. is not intended in any normative sense as a definitive framework; had Giddens himself intended such a framework to balance his structurational model, he might surely have provided us with one. However, in as much as Giddens' ideas are applied in a variety of ways to illuminate social issues within various disciplines, without making normative claims about his original intentions (as Orlikowski notes in her 1992 paper, structuration itself was not designed with IS researchers in mind), the Dimensions of the duality of social and biographical structure in Fig. 2. is intended primarily as a way of illustrating that the interrelationships between several of his key ideas concerning biographical motivation deserve greater attention within the IS canon. Moreover, these ideas offer particular opportunities for those who seek to apply his structurational model, which Fig.2. shows such ideas to complement.

Two clear implications arise from the illustration of the urgent need for a more committed engagement by IS researchers with the subjective and, more specifically, from the framework in Fig. 2 for rehabilitating Giddens' broader ideas within structurational accounts of technology. The first implication is heavily practical: the framework in Fig. 2 drawing on Giddens' ideas offers a potentially useful way for IS researchers wishing to acknowledge and address within their own work the growing importance of considerations of the subjective within adjacent clinical and practice-based social sciences. Revisiting Giddens at this point for this purpose is arguably a useful activity for those IS scholars wishing to engage with subjective dimensions of social-technical experience, for two reasons. First, I hope to have demonstrated a striking resemblance between more recent interdisciplinary work confirming 
the need for a more committed engagement with the subjective, and Giddens' core concerns with biographical time, reflexive thought and feeling, and emergent structures of mutual intelligibility. Second, as psychologist-turned sociologist, Giddens' work offers not only detailed engagement with these concepts but, crucially, a thorough and unique treatment of their interrelationship with emergent social structure. In aligning and articulating Giddens' broader writings on the subjective with the comparatively narrower dimensions of his structurational model with which IS researchers are more familiar, it is hoped that Fig. 2 may help in making some of these ideas more accessible within the genre.

It is arguable that greater accessibility and use of these ideas is particularly timely within the present IS architectural era, in which traditionally integrated 'big IT' is becoming displaced progressively by consumer-oriented, modular, and highly configurable IS service offerings and applications that are more highly woven into users' everyday lives (Fishenden and Thompson 2012, forthcoming). Although a structurational perspective on IT is essentially non-deterministic across all technologies, it remains nonetheless that the modularity of newer, service- and cloud- based IT architectures offers unprecedented plasticity around consumer choice. In a progressively commoditised IT world where consumers are able to choose from several options, all of which are capable of performing the same (cognitively-determined), increasingly standardised functions, it is likely that intuitive, emotive appeal of a non-cognitive nature will play an increasingly important role in conditioning technological adoption.

Under such conditions, for example, explicit consideration by IS designers of modalities within the 'biographical realm' outlined in Fig. 2 might offer opportunities for deliberately factoring intuitive, non-cognitive considerations into the design process, thereby improving a product's intuitive appeal, and resulting chance of success. Similarly, it is suggested that IS researchers may be able more fully to explain users' reactions to, and stance towards, technological choices with which they may be confronted by engaging with the bottom, as well as the top half, of Fig. 2. For example, focus groups or interviews seeking to elicit how people feel about modular, platform-based technologies such as Force.com are likely to gain a more accurate sense of these technologies' likely adoption, particularly where such technologies are also accessible via peoples' personal smartphones and other PDAs and must thus operate intuitively if they are to be used effectively. Such an approach appears very different to traditional systems design approaches such as DSDM (dynamic systems design methodology) or SSM (soft systems methodology) that might have been used in the development of equivalent ERP systems in the past.

In this way, when designing or studying increasingly plastic, consumer-driven technologies that increasingly span both domestic and organisational environments, 
engagement as shown in Fig. 2 with users' self-identity (and the notion of autobiography), layered consciousness (and the notion of embodied, 'unthinking' routines with which people are comfortable), and the 'front regions' of presentation of self (and thus the routinised attitudes that support these) are likely to constitute a very useful counterbalance to more traditional consideration of norms (and supporting social structures of legitimation), facilities (and social structures of domination), and interpretive schemes (and social structures of signification). This is arguably especially the case where users are increasingly purchasing, and even configuring, technologies themselves. Indeed, for these reasons it is perhaps not farfetched to suggest that traditional accounts of social-technical interaction offering solely 'social' explanations of emergent communication, power, and sanction as shown in Fig. 2 are likely to prove increasingly insufficient in attempting to explain the current growth, usage patterns and often fickle user loyalties (Localytics 2011) of modular, utility technology.

The second, strategic, contribution is a more general broadening of current discourse within the IS community about the social-material relationship itself, to admit an adjustment, or rebalancing, of emphasis involving greater acknowledgment of the role of reflexive production and reproduction of biographical structures within social generation. In particular, the concept of 'sociomateriality' (e.g. Orlikowski 2007) is currently attracting growing interest within the IS research community, a formulation that, whilst not explicitly conflating social and subjective, often uses these concepts interchangeably. This is perhaps unsurprising, given the term's dyadic formulation comprising 'social' and 'material', a formulation in which explicit acknowledgment of the subjective is absent. From the standpoint set out in this paper, there is an attendant danger that any such dyadic formulation comprising exclusively 'social' and 'material' dimensions risks downplaying or even overlooking latent subjective structures, yielding accounts of social reality that remain primarily cognitive in orientation, with the results for IS studies, in particular, that were outlined during the review of the literature in section one. From this perspective, it is perhaps a shame that the word 'sociomateriality' works so much more seductively in an etymological sense than any alternative formulation attempting to incorporate the materially-implicated nature of two types of (social and biographical) latent structure.

Accordingly, it is suggested that a potentially fruitful direction for further theoretical development of sociomateriality and other practice-based lenses within IS research would be a broadening of dyadic social-material conceptual frameworks to include a more explicit engagement with epistemologically subjective, as well as objective, dimensions, fused in the reflexive intentionality of practice. Such a broadening would necessarily involve conscious dialogue with emerging research from within neighbouring disciplines to produce IS research that is neither 'primarily sociological', nor 'primarily psychological', but concerned with a 
balanced engagement with the important role played by emergent structures on both sides in the practice of organising. Indeed, there are already tentative signs of attempts from within both disciplines to 'lean towards' one another: for example, the organizational psychologist Elfenbein (2007) has developed a 'process view of emotion' intended to allow researchers to "move beyond the individual level into dyads, groups, and even organizations. In the process framework, these interpersonal and higher levels appear primarily in terms of the norms that guide emotion regulation" (2007:368, my italics). Similarly, from within Sociology, Stones' (2005) book Structuration Theory seeks explicit engagement in parts with more subjective, psychological components of social generation. Such attempts point to the possibility of IS studies founded on a balanced engagement between sociological and psychological perspectives.

\section{Conclusion}

This paper has argued, from a theoretical perspective, that the way in which social structure is always interpreted by, and moderated through affectively-experienced biographical narrative forms a core theme of Giddens' work, in spite of the relative absence of such concerns within his Dimensions of the duality of structure. Accordingly, the framework presented in this paper is intended as a thought piece to address directly the issue of biographical affect within IS and organizational environments - an issue that has recently begun to attract increasing attention within the organizational and IS canon as it focuses increasingly on the notion of practice. In seeking to place the structurational model within the broader, more balanced context of Giddens' work on the self, it is hoped that this paper may contribute further to the ongoing debate about the application of Giddens' ideas to a range of more contemporary IS and wider organizational concerns.

In addition, I have presented a range of broader evidence from within neighbouring disciplines, as well as from within the IS canon itself, that there is a need for a more urgent and comprehensive project within IS research more generally to theorise and address components of subjectivity. In particular, I have sought to move beyond mere acknowledgment of the underresearched nature within IS of key concepts relating to subjectivity, by drawing attention to the analytical notion of biographical affect. Biographical affect is not intended as a new construct, but as a recognition of, and shorthand for, those components of our non-cognitive subjectivity that are becoming acknowledged by many as conditioning of our present actions. Such components include our continually maintained self-identities, or narratives of our past, and the way in which we may non-cognitively or emotively select from those inscribed properties of our narrative past those that feel relevant, 
which are foregrounded in the form of our directed, 'expectant' stance towards our surroundings. Both we, and our surroundings, emerge altered from the encounter:

"The potency and influence of the media of regulation is always conditional upon organizational members' responses to them. Discourses may be comparatively familiar and readily interpreted within an on-going identity narrative and associated emotional condition; or they may be disruptive of it...People may distance themselves from the company as a key source of identification and draw upon the occupation, subunit or non-work sources of self-definition ("I am a family man rather than a career person")" (Alvesson and Willmott 2002:27).

It is hoped that some of the concepts presented in this paper may prove fruitful for IS researchers in the future, as we study interrelationships between ever more portable, consumer-based and personally-configured technologies, and our own diverse, and continually evolving, sources of self-identification and self-definition as human beings. 


\section{References}

Adam M, Hagenau M, Neumann D, Weinhardt C: Emotions in Electronic Auctions - A Physio-Economic Approach on Information Systems 2008 (16th European Conference on Information Systems (ECIS), 2008, Galway, Ireland)

Ajzen, I. (2001). 'Nature and operation of attitudes'. Annual Review on Psychology 52: 2758.

Alvarez, R. (2008). 'Examining Technology, Structure and Identity During an Enterprise System Implementation'. Information Systems Journal 18: 203-224.

Alvesson, M., \& Willmott, H. (2002). 'Identity Regulation as Organizational Control: Producing the Appropriate Individual'. Journal of Management Studies 39(5): 619-644.

Avgerou, C., Ciborra, C., and Land, F. (Eds.). (2004). The Social Study of Information and Communication Technology, Oxford University Press, Oxford.

Avgerou, C., and McGrath, K. (2007). 'Power, rationality, and the art of living through sociotechnical change'. Management Information Systems Quarterly, 3 (2): 293-315.

Barbalet, J.M. (2001). Emotion, Social Theory and Social Structure: A Macrosociological Approach. Cambridge: Cambridge University Press.

Barrett, M., \& Walsham, G. (1999). 'Electronic Trading and Work Transformation in the London Insurance Market'. Information Systems Research 10(1): 1-23.

Barrett, M., \& Scott, S.V. (2004). 'Electronic Trading and the Process of Globalization in Traditional Futures Exchanges: A Temporal Perspective'. European Journal of Information Systems 13: 65-79.

Bhattacherjee, A., (2001). 'Understanding information systems continuance: an expectationconfirmation model'. Management Information Systems Quarterly 25(3): 351-370.

Blackler, F. (1995). 'Knowledge, Knowledge Work and Organizations: An Overview and Interpretation'. Organization Studies 16(6): 1021-1046.

Blackler, F., Crump, N., and McDonald, S. (2000) 'Organizing processes in complex activity networks'. Organization 7(2): 277-300. 
Boland, R.J. (1993). 'Accounting and the interpretive act'. Accounting, Organizations and Society 18(2/3): 125-146.

Bourdieu, P. (1977). Outline of a Theory of Practice. Cambridge: Cambridge University Press.

Brave, S. \& Nass, C. (2002). Emotion in human-computer interaction. In Jacko, J. \& Sears, A. (Eds.), Handbook of human-computer interaction (pp. 251-271). New York: Lawrence Erlbaum Associates.

Brooks, L., and Atkinson, C. (2004). Structuration in Research and Practice: Representing Actor Networks and Their Structured Orders and Translations. In B. Kaplan, D. Truex, D. Wastell, T. Wood-Harper, \& J. I. DeGross (Eds.), Information Systems Research: Relevant Theory and Informed Practice, (pp. 389-409). Boston: Kluwer Academic Publishers,.

Callon, M. (1986). 'Some Elements in a Sociology of Translation: Domestication of the Scallops and Fishermen of St Brieuc Bay'. In J. Law, (Ed.), Power, Action and Belief. London: Routledge.

Carlsen, A. (2006). 'Organizational Becoming as Dialogic Imagination of Practice: The Case of the Indomitable Gauls'. Organization Science 17(1): 132-149.

Chia, R. (2002). 'Essai: Time, duration and simultaneity: rethinking process and change in organizational analysis'. Organization Studies 23(6): 863-868.

Ciborra, C. U. (2002). The Labyrinths of Information: Challenging the Wisdom of Systems, Oxford: Oxford University Press,

Ciborra, C., \& Willcocks, L. (2006). 'The mind or the heart? It depends on the (definition of) situation'. Journal of Information Technology 21: 129-139.

Damasio, A. (1994). Descartes' Error: Emotion, Reason and the Human Brain. New York: G. P.

Damasio, A. (1999). The feeling of what happens - Body, emotion and the making of consciousness. London: Vintage.

Davis, F.D. (1989). 'Perceived usefulness, perceived ease of use, and user acceptance of information technology'. Management Information Systems Quarterly 13(3): 319-340. 
Davis, F.D., Bagozzi, R.P., \& Warshaw, P.R. (1989). 'User acceptance of computer technology: a comparison of two theoretical models'. Management Science 35(8): 982-1002.

DeSanctis, G., and Poole, M. S. (1994). 'Capturing the Complexity in Advanced Technology Use: Adaptive Structuration Theory'. Organization Science 5(2): 121-147.

Dobson, P. J. (2001). 'The Philosophy of Critical Realism: An Opportunity for Information Systems Research,' Information Systems Frontiers 3(2): 199-210.

Emirbayer, M., and Mische, A. (1998). 'What is agency?'. American Journal of Sociology 103(4): 962-1023.

Fay, E., \& Puyou, F-R. (2006). 'Putting the Subjective Experience of Management Accounting Information Systems back into Organization Research: A Contribution Based on Michel Henry's Phenomenology'. Paper presented at the 8th Interdisciplinary Perspectives on Accounting Conference, Cardiff, 10-12 July.

Fishenden, J., and Thompson, M. (forthcoming) 'Digital government, Open architecture, and innovation: Why public sector IT will never be the same again'. Journal of Public Administration, Research and Theory

Fineman, S. 2008. (Ed.) The Emotional Organization: Passions and Power. London: Blackwell.

Gal, U., K. Lyytinen, \& Y. Yoo. (2008). 'The Dynamics of IT Boundary Objects, Information Infrastructures, and Organisational Identities: The Introduction of $3 \mathrm{~d}$ Modelling Technologies into the Architecture, Engineering, and Construction Industry'. European Journal of Information Systems, 17: 290-304.

Gal, U., \& Kjaergaard, A. (2009). 'Identity in Organizations: A Review of Information Systems Research', in 17th European Conference of Information Systems: 1-14.

Giddens, A. (1976). New Rules of Sociological Method. Stanford: Stanford University Press.

Giddens, A. (1981). A Contemporary Critique of Historical Materialism. London: Macmillan.

Giddens, A. (1984). The Constitution of Society: An Outline of the Theory of Structuration. Cambridge: Polity. 
Giddens, A. (1991). Modernity and Self-identity: Self and Society in the Late Modern Age. Cambridge: Polity.

Giddens, A. (1994). Beyond Left and Right: The Future of Radical Politics. Cambridge : Polity.

Giddens, A. (1998) The Third Way. The Renewal of Social Democracy. Cambridge : Polity.

Giddens, A, \& Pierson, C. (1998). Conversations with Anthony Giddens: Making sense of Modernity. Stanford: Stanford University Press.

Giddens, A. (2000) The Third Way and its Critics. Cambridge : Polity.

Goffman, E. (1974). Frame Analysis: An Essay on the Organization of Experience. New York: Harper and Row.

Hayes, M., \& Walsham, G. (1999). 'Shifting customer-engineering relationships: Archteypes of identities and the role of information systems'. Working Paper WP25/99, The Judge Institute of Management Studies, Cambridge: University of Cambridge.

Holland, D.W., Lachicotte, D. Skinner, \& Cain, C. (1998). Identity and Agency in Cultural Worlds. Cambridge, MA: Harvard University Press.

Introna, L. D. (1996). 'Commentary on the Intellectual Structures of Information Systems Development by Hirschheim, Klein and Lyytinen'. Accounting, Management and Information Technologies 6(1/2): 87-97.

Introna, L. (1997). Management Information and Power. London: Macmillan.

Jones, M.R. (1999). Structuration Theory. In Currie, WJ and. Galliers, R.D. (Eds)., Rethinking Management Information Systems (pp.103-135). Oxford: Oxford University Press.

Jones, M.R. and Karsten, H. (2008). 'Review: Giddens's structuration theory and information systems research.. Management Information Systems Quarterly, 32(1): 127-157.

Kant, I. (1933). Critique of Pure Reason, Trans. N. Smith. London: Macmillan.

Kim, H-Wl, Chan, H. C., and Chan, Y.P. (2007). 'A balanced thinking-feelings model of information systems continuance'. International Journal of Human-Computer Studies 65: 511-525. 
Knights, D., \& Willmott, H.C. (1985). 'Power and identity in theory and practice'. Sociological Review 33(1): 22-46.

Knorr-Cetina, K. (2001) 'Objectual practice', in T.R. Schatzki, Knorr-Cetina, K., \& Von Savigny, E. (Eds.), The practice turn in contemporary theory (pp.175-188). London and New York: Routledge.

Latour, B. (1987). Science in Action: How to follow scientists and engineers through society. Cambridge, MA: Harvard University Press.

Lave, J. (1988). Cognition in Practice. Cambridge: Cambridge University Press.

Localytics (2010). Mobile App Users Are Both Fickle And Loyal: Study. http://techcrunch.com/2011/03/15/mobile-app-users-are-both-fickle-and-loyal-study/

Maznevski, M.L., \& Chudoba, K.M. (2000). 'Bridging Space over Time: Global Virtual Team Dynamics and Effectiveness'. Organization Science 11: 473-492.

McDermott, R. (1999). 'Why information technology inspires but cannot deliver knowledge management'. California Management Review 41(4): 103-117.

McGrath, K. (2006). 'Affection Not Affliction: The Role of Emotions in Information Systems and Organizational Change'. Information and Organization 16(4): 277-303.

Orlikowski, W. (1992). 'The duality of technology: rethinking the concept of technology in organizations'. Organization Science 3(3): 398-427.

Orlikowski, W. \& Robey, D. (1991). 'Information technology and the structuring of organizations'. Information Systems Research 2(2): 143-169.

Orlikowski, W. J. (2000). 'Using Technology and Constituting Structures: A Practice Lens for Studying Technology in Organizations,' Organization Science 11(4): 404-428.

Orlikowski, W.J. (2007). 'Sociomaterial Practices: Exploring Technology at Work'. Organization Studies 28: 1435-1448.

Pettigrew, A. (1995). 'Longitudinal field research on change: theory and practice'. Organization Science 1(3): 267-292.

Polanyi, M. (1958). Personal Knowledge: Towards a Post-critical philosophy. London: Routledge. 
Polanyi, M. (1967). The Tacit Dimension. New York: Doubleday.

Poole, M. S., and DeSanctis, G. (2004). Structuration Theory in Information Systems Research: Methods and Controversies. In Whitman, M.E., \& Woszcynski, A. (Eds). Handbook of Information Systems Research, (pp. 206-249). Hershey, PA: Idea Group,.

Robey, D., \& Markus, M. L. (1984). 'Rituals in Information System Design,'. Management Information Systems Quarterly 8(1): 5-15.

Schank, R., \& Abelson, R. (1977). Scripts, Plans, Goals, and Understanding. Hillsdale, N.J: Erlbaum.

Schatzki, T. (2001) 'Introduction: Practice theories', in In Schatzki, T., Knorr-Cetina, K, \& Von Savigny, E. (Eds.) The practice turn in contemporary theory. (pp.1-14). London: Routledge.

Solms, M., \& Turnbull, O. (2002). The brain and the inner world: An introduction to the neuroscience of subjective experience. New York: Other Press.

Simpson, B. (2009). 'Pragmatism, Mead, and the practice turn'. Organization Studies 30(12): 1329-1347.

Sturdy, A. (2003). 'Knowing the unknowable? A discussion of methodological and theoretical issues in emotion research and organization studies'. Organization 10(1): 81-105.

Sun, Heshan and Ping Zhang (2006). The Role of Affect in IS Research: A Critical Survey and a Research Model, in HCI. In Zhang, P. and Galletta, D. (Eds.), MIS (I): Foundations, Series of Advances in Management Information Systems, Zwass, V. (editor-in-chief), M.E. Sharpe.

Thompson, M., (2002). 'Cultivating meaning: interpretive fine-tuning of a South African health information system'. Information and Organization 12(3): 183-211.

Thompson, M. (2011). 'Ontological shift or ontological drift? Reality claims, epistemological frameworks, and theory generation in organization studies'. Academy of Management Review 36(4): 754-773.

Tsoukas, H. (1996). 'The firm as Distributed Knowledge System: A Constructionist Approach'. Strategic Management Journal 17 (Winter Special Issue): 11-25. 
Tsoukas, H., \& Chia, R. (2002). 'On organization becoming: rethinking organizational change'. Organization Science 13(5): 567-582.

Van Akkeren, J., \& Rowlands, B. (2007). 'An Epidemic of Pain in an Australian Radiology Practice'. European Journal of Information Systems, 16: 695-711.

Wang, C-Y, Chou, S. -c.T, \& Chang, H-C. (2009). 'Emotion and Motivation: Understanding User Behavior of Web 2.0 Application'. Sixth International Conference on Information Technology: New Generations, ITNG '09, Las Vegas, 27-29: 1341-1346.

Walsham, G. Globalization and IT: Agenda for Research. In Baskerville, R., Stage, J., \& DeGross, J. (Eds.), Organizational and Social Perspectives on Information Technology. Kluwer, Boston, 2000, pp. 195-210.

Walsham, G. (2001). Making a World of Difference: IT in a Global Context. Chichester: Wiley.

Wertsch, J. (1981). The Concept of Activity in Soviet Psychology. in J. Wertsch, (Ed). The Concept of Activity in Soviet Psychology. Armonk, N.Y: M.E.Sharpe.

West, M. (2007). Feeling, being, and the sense of self: A new perspective on identity, affect and narcissistic disorders. London: Karnac.

Williams, S.J., \& Bendelow, G.A. (1998). The lived body: Sociological themes, embodied issues. London: Routledge. 